\title{
Five minutes from disaster
}

\author{
Nuclear weapons, nuclear power and climate change are driving the march of the Doomsday Clock \\ towards midnight.
}

The hands of the Doomsday Clock have moved a minute closer to midnight. Established by the Bulletin of the Atomic Scientists, since 1947 the clock has symbolized the state of world affairs, with the minutes left before the midnight hour representing how close the planet may be veering towards disaster. As the Bulletin itself was founded by Manhattan Project physicists in the wake of the atomic bombings of Hiroshima and Nagasaki, it has been primarily concerned with issues surrounding the use and proliferation of nuclear weaponry. But the current setting of the Doomsday Clock, at five minutes to midnight, now reflects a greater spectrum of global threat, notably that of climate change.

In 1947, the clock was set initially at seven minutes to midnight. By 1949, it stood at three minutes to the hour, as the Soviet Union stepped up its nuclear weapons testing and the arms race began, and by 1953 the world was a mere two minutes from doomsday. However, in 1963 the clock was wound back to 12 minutes to midnight when, one year on from the Cuban missile crisis, the Soviet Union and the United States signed the Partial Test Ban Treaty, putting an end to all atmospheric testing of nuclear weapons. The signing of the Strategic Arms Reduction Treaty by these superpowers in 1991 rolled the clock hands back to a happy 17 minutes to the hour.

Since then, although the Cold War had come to an end, the clock hands have mostly crept forward. The board of directors of

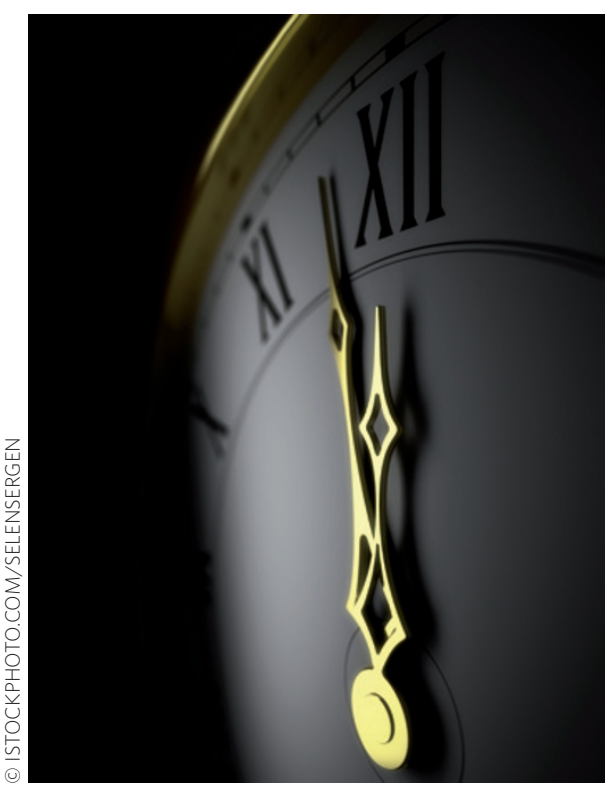

Certainly the outcome of the most recent round of climate talks (J. Tollefson, Nature 480, 299-300; 2011), held in Durban, South Africa in December 2011, gives little cause for optimism. Intense late-night bargaining produced the Durban Platform for the negotiation of a new climate treaty by 2015 but the Kyoto Protocol it succeeds will have expired by the end of this year. Still no major carbon-producing economy outside Europe is committed to a reduction in emissions.

Another cause for concern for the Bulletin's board straddles the issues of both nuclear materials and the environment that is, the safety of nuclear power. The earthquake and tsunami that hit Japan in March 2011 caused meltdown at the Fukushima Daiichi nuclear power plant, and revealed how poorly prepared its operators were to manage the disaster. Investigations into the incident have been hampered by a lack of transparency that led Japanese politicians, including former Prime Minister Yukio Hatayama, to call (T. Taira and

the Bulletin of the Atomic Scientists, who are tasked with setting the clock, have signalled their concern not only over the failure to curtail weapon stocks in the United States and Russia, but also over the spread of nuclear capability - notably to India, Pakistan and North Korea - and the developing nuclear ambitions of Iran. But the advance of the clock by two minutes in 2007 was also driven by another worry: that damage to the planet by carbonemitting technologies could be catastrophic and "irremediable". Y. Hatoyama, Nature 480, 313-314; 2011) for nationalization of the power plant. (Brighter news, as Nature Physics goes to press, is that the Main Ring of J-PARC's accelerator complex at Tokai is resuming operation following the disruption, particularly to the laboratory's neutrino-physics programme, caused by last year's earthquake.)

The Doomsday Clock may be merely a symbol, but to all it is a means of remaining mindful of the dangers of the past and aware of the dangers of the present.

\section{Out of the darkness}

\section{The web blackout symbolized concern over potential legislation, which we share.}

For one day last month, the Englishlanguage pages of Wikipedia went dark. The blackout of that site and an estimated 7,000 others was in protest against the Stop Online Piracy Act (SOPA), on the slate in the US Congress. Days later, the consideration of the bill in its present form was halted, and a vote on the related Protect IP Act (PIPA) postponed.

The protest and public outcry at the prospect of web 'censorship' was unprecedented. But the Obama administration had already voiced its disapproval in a White House statement refusing support for legislation that "reduces freedom of expression, increases cybersecurity risks or undermines the dynamic, innovative global Internet." And in a debate ahead of last month's contentious South Carolina primary, all four candidates for the Republican presidential nomination came out against the acts.

The Research Works Act, introduced in Congress in December 2011, is also causing concern among scientists and the library community. Nature Publishing Group, to which Nature Physics belongs, does not support SOPA, PIPA or the Research Works Act - statements on its position can be found at http://www.nature.com/npg_/ press_room/index.html. 